\title{
ALAT KOREKSI FAKTOR DAYA PADA INSTALASI LISTRIK RUMAH TINGGAL 3 PHASA BERBASIS MIKROKONTROLER ATMega 8535
}

\author{
Hatma Rudito ${ }^{1)}$, Talib Bini ${ }^{2)}$ \\ ${ }^{1,2}$ Jurusan Teknik Elektro, Politeknik Negeri Ujung Pandang
}

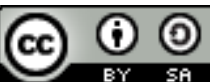

\begin{abstract}
Abstrak
Kebutuhan akan penyediaan daya listrik berkualitas baik adalah mutlak. Secara umum, daya listrik berkualitas baik sebesar 0,8 sampai 1. Karena kebutuhan pelanggan PLN menggunakan beban induktif, maka dapat menyebabkan faktor daya menjadi rendah, dan akan menyebabkan pemanfaatan energi listrik menjadi tidak maksimal. Untuk mengoreksi faktor daya tersebut agar mencapai nilai yang mendekati ataupun menjadi berkualitas baik, maka dilakukan cara pemasangan rangkaian kapasitor (capacitor bank). Pemakaian beban induktif pada pelanggan PLN tidak selalu sama, maka dirancang suatu alat untuk memperbaiki nilai faktordaya secara otomatis berdasarkan perubahan beban induktif pada rumah tinggal industri dengan menggunakan mikrokontroler. Mikrokontroler tersebut yang akan mengontrol pengaktifan kapasitor. Koreksi faktor daya terdiri dari serangkaian sistem minimum mikrokontroler, sensor ACS712, driver relay, dan capacitor bank.
\end{abstract}

Kata kunci: mikrokontroler, faktor daya, driver relay, capacitor bank

\section{PENDAHULUAN}

Peningkatkan nilai faktor daya dapat dilakukan dengan pemasangan sebuah atau beberapa rangkaian kapasitor. Pada konsumen rumah tinggal, sudah mulai terdapat pemasangan rangkaian kapasitor, walau hanya beberapa rumah. Namun pemasangan rangkaian kapasitor ini juga mempunyai keterbatasan, karena rangkaian kapasitor yang dipasang memiliki nilai kapasitansi yang cenderung tetap sedangkan konsumen rumah tinggal tidak selalu menggunakan beban induktif yang sama pada waktu yang sama pula. Dalam hal ini, rangkaian kapasitor hanya mampu bekerja maksimum sesuai dengan nilai kapasitansinya. Pada saat beban induktif bertambah, maka kemampuan perbaikan faktor daya oleh rangkaian kapasitor juga berkurang.

Dengan melihat kendala di atas, maka dirancang suatu alat untuk mengoreksi nilai faktor daya secara otomatis berdasarkan perubahan beban induktif pada rumah tinggal industri dengan menggunakan mikrokontroler.

Beberapa cara untuk menganalisis menggunakan persamaan sebagai berikut :

Rumus:

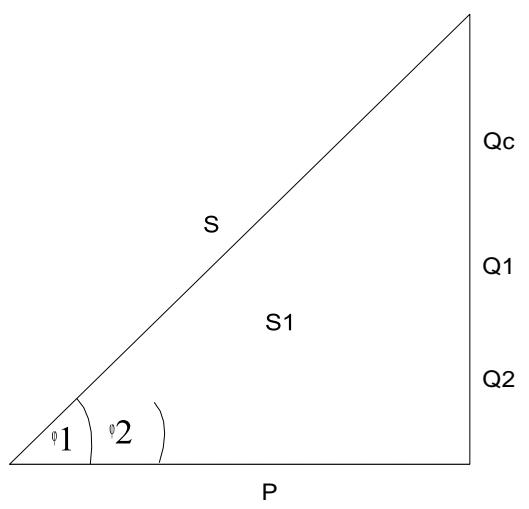

Gambar 1. Analisa koreksi faktor daya

Ket:

$\mathrm{Q}_{1}=\mathrm{Q}$ induktif

$\mathrm{Q}_{2}=\mathrm{Q}$ akhir 
$\mathrm{Q}_{\mathrm{c}}=\mathrm{Q}$ kapasitif

$\operatorname{Tan} \varphi=\frac{P}{Q}$

$\mathrm{Q}=\mathrm{P} \cdot \tan \varphi$

$\mathrm{Q}_{\mathrm{c}}=(\mathrm{P} \cdot \tan \varphi 1)-(\mathrm{P} \cdot \tan \varphi 2)$

$=P \cdot \tan (\varphi 1-\varphi 2)$

$\mathrm{C}=\frac{\mathrm{Q}_{\mathrm{c}}}{\mathrm{V}^{2} \cdot 2 \pi \mathrm{f}}$

$$
=\frac{Q_{c}}{220^{2} .2 \pi f}
$$

\section{PERANCANGAN}

Sistim ini dirancang untuk mengantisipasi perubahan beban induktif dirumah tinggal, sehingga fakator dayanya berkisar antara 0.8 sampai 1 adapun ganbar rangkaian lengkapanya daat dilihat sebagai berikut :

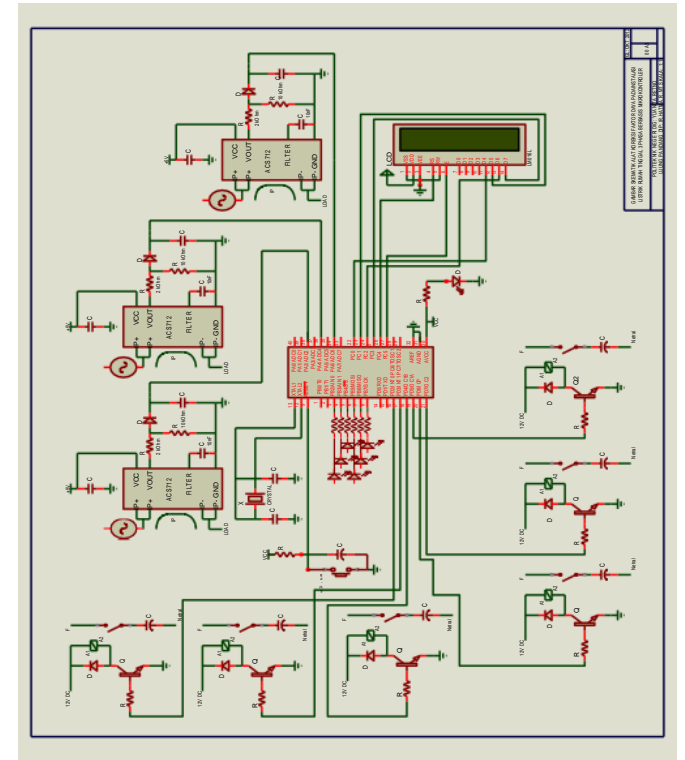

Gambar 1. Rangkaian lengkap

Dan gambar setalah dibuat dalam bentuk rankaian adalah sebagai berikut :

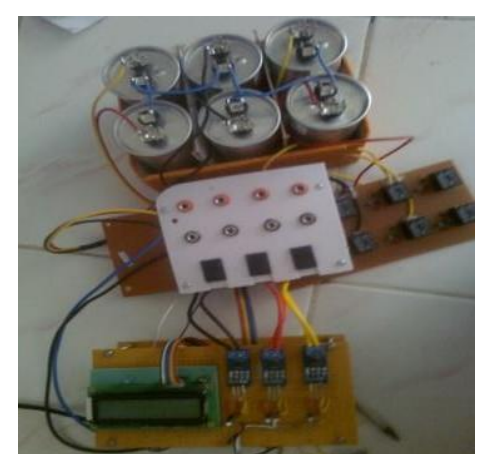

Gambar 2. Rangkaian Alat Koreksi

\section{HASIL PENELITIAN DAN PEMBAHASAN}

Tabel .1 Hasil penelitian

\begin{tabular}{clcccc}
\hline No & Beban & $\begin{array}{c}\text { Pf } \\
\text { Sebelum }\end{array}$ & $\begin{array}{c}\text { Daya } \\
(\mathbf{W})\end{array}$ & $\begin{array}{c}\text { Pf } \\
\text { Sesudah }\end{array}$ & $\begin{array}{c}\text { Kapasitor } \\
\text { Aktif } \\
(\mu \mathrm{F})\end{array}$ \\
\hline \multirow{2}{*}{$\begin{array}{l}\text { Mesin Jahit } \\
(\text { dinamo) }\end{array}$} & 0,5 & 200 & 0,88 & 20 \\
\hline 2 & Mesin Cuci & 0,4 & 150 & 0,9 & 40 \\
\hline & $\begin{array}{l}\text { Mesin Cuci } \\
+ \text { Mesin }\end{array}$ & & & & \\
3 & $\begin{array}{l}\text { Jahit } \\
4\end{array}$ & 0,53 & 350 & 0,87 & 40 \\
\hline $\begin{array}{l}\text { Motor 3 } \\
\text { phasa (A) }\end{array}$ & 0,76 & 1350 & 0,85 & 20 \\
\hline 5 & $\begin{array}{l}\text { Motor 3 } \\
\text { phasa (B) }\end{array}$ & 0,2 & 1000 & 0,92 & 75 \\
\hline
\end{tabular}

Tabel.2 Database beban dengan ACS712

\begin{tabular}{clccc}
\hline No & Beban & $\begin{array}{c}\text { Teg. } \\
\text { ACS } \\
\mathbf{7 1 2 ~ a}\end{array}$ & $\begin{array}{c}\text { Teg. } \\
\text { ACS712 b }\end{array}$ & $\begin{array}{c}\text { Teg. } \\
\text { ACS712 c }\end{array}$ \\
\hline $\begin{array}{l}\text { Mesin } \\
1\end{array}$ & $\begin{array}{l}\text { Jahit } \\
\text { (dinamo) }\end{array}$ & 2,49 & 2,52 & 2,52 \\
\hline 2 & $\begin{array}{l}\text { Mesin } \\
\text { Cuci }\end{array}$ & 2,50 & 2,54 & 2,54 \\
\hline & $\begin{array}{l}\text { Mesin } \\
\text { Cuci + } \\
3\end{array}$ & 2,54 & 2,58 & 2,58 \\
\hline $\begin{array}{l}\text { Mesin } \\
\text { Jahit }\end{array}$ & $\begin{array}{l}\text { Motor 3 } \\
\text { phasa (A) }\end{array}$ & 2,687 & 2,717 & 2,717 \\
\hline 5 & $\begin{array}{l}\text { Motor 3 } \\
\text { phasa (B) }\end{array}$ & 2,72 & 2,75 & 2,75 \\
\hline
\end{tabular}

\section{PEMBAHASAN DAN ANALISIS}

Untuk menganalisis data beban, yaitu Mesin Sulam. 


$$
\begin{aligned}
\mathrm{Pf} & =0,5 \rightarrow \varphi=60 \\
\mathrm{P} & =200 \text { watt } \\
\mathrm{Pf}_{1} & =0,85 \rightarrow \varphi_{1}=31,78 \\
\mathrm{Pf}_{2} & =1 \rightarrow \varphi_{2}=0 \\
\mathrm{Q}_{\mathrm{c} 1} & =\mathrm{P} \cdot \tan \left(\varphi-\varphi_{1}\right) ; \\
\mathrm{Q}_{\mathrm{c} 2} & =\mathrm{P} \cdot \tan \left(\varphi-\varphi_{2}\right) \\
& =200 \cdot(1,73-0,61) \\
& =200 \cdot(1,73-0) \\
& =200 \cdot 1,12 \\
& =346 \mathrm{VAR} \\
& =224 \mathrm{VAR} \\
\mathrm{C}_{1} & =\frac{\mathrm{Q}_{\mathrm{c} 1}}{\mathrm{~V}^{2} \cdot 2 \pi \mathrm{f}} \\
\mathrm{C}_{2} & =\frac{\mathrm{Q}_{\mathrm{c} 2}}{\mathrm{~V}^{2} \cdot 2 \pi \mathrm{f}} \\
& =\frac{224}{220^{2} \cdot 314} \\
& =\frac{346}{220^{2} .314} \\
& =1,47 \times 10^{-5} \mathrm{~F} \\
& =2,27 \times 10^{-5} \mathrm{~F} \\
& =14 \mu \mathrm{F} \\
& =22,7 \mu \mathrm{F}
\end{aligned}
$$

Kapasitor yang digunakan untuk beban tersebut bernilai $40 \mu \mathrm{F}$, dengan $\mathrm{Pf}=0,89$.

$\mathrm{C}=20 \mu \mathrm{F}=2 \times 10^{-5} \mathrm{~F}$

$\mathrm{Pf}=0,88$

$\mathrm{P}=200$ watt

$\mathrm{C}=\frac{\mathrm{Q}_{\mathrm{c}}}{\mathrm{V}^{2} \cdot 2 \pi \mathrm{f}}$

$\mathrm{Q}_{\mathrm{c}}=\mathrm{C} . \mathrm{V}^{2} .2 \pi \mathrm{f}$

$$
=2 \times 10^{-5} \cdot 220^{2} \cdot 314
$$$$
=303,952 \mathrm{VAR}
$$

$\operatorname{Tan} \varphi=\frac{\mathrm{P}}{\mathrm{Q}_{\mathrm{c}}}$

$$
\begin{aligned}
=\frac{200}{303,952} \\
=0,65 \\
\varphi=\operatorname{Tan}^{-1}(0,65) \\
=33,02
\end{aligned}
$$

$$
\begin{aligned}
\mathrm{Pf} & =\operatorname{Cos} \varphi \\
& =\operatorname{Cos} 33,02 \\
& =0,83
\end{aligned}
$$

Dengan cara yang sama rumus analisis juga berlaku untuk tiap beban lainnya pada tiap fasa berbeda (R, S, dan $T)$.

Untuk mendapatkan dan menampilkan hasil dari alat perbaikan faktor daya ini, diawali dengan cara membuat database, dimana database tersebut akan diinput kedalam ATMega 8535. Pengambilan data dimulai dengan mencatat jenis beban yang akan digunakan, seperti Motor Induksi mesin sulam, mesin cuci, dan lainnya. Alat utama yang digunakan untuk pengambilan data adalah $p f$ (power factor) meter, dan rangkaian sistem ATMega 8535 (lengkap dengan sensor ACS712 dan LCD).

Data yang diambil dari beberapa percobaan berupa nilai daya dan $p f$ dari masingmasing beban serta tegangan keluaran dari sensor arus ACS712. Data daya dan $p f$ beban digunakan untuk menentukan nilai dari kapasitor yang akan digunakan untuk perbaikan faktor daya beban itu, sedangkan tegangan keluaran dari sensor arus ACS712 digunakan untuk proses inisialisasi $p f$ dari beban.

Setelah proses pengambilan data dan penentuan nilai kapasitor, dilakukan percobaan dengan memasang kapasitor dengan nilai yang mendekati hasil perhitungan. Dimana pada percobaan tersebut hasil dari pemasangan kapasitor dilihat dengan menggunakan $p f$ meter dan membandingkannya dengan hasil perhitungan.

Untuk proses akhir, data tegangan keluaran ACS712 diinput ke dalam program, 
dan nantinya tegangan tersebut akan mewakili jenis beban dan faktor dayanya, yang kemudian ditampilkan ke display LCD, selang beberapa detik kemudian ATMega 8535 melaksanakan instruksi perbaikan faktor daya dan faktor daya yang ditampilkan berubah menjadi nilai dari hasil proses perbaikan faktor daya.

\section{KESIMPULAN}

1. Mikrokontroler mampu mengontrol pengaktifan kapasitor bank yang nilainya sesuai dengan kebutuhan beban induktif yang akan mengoreksi faktor daya secara otomatis.

2. Untuk beban yang tidak konstan dapat dilakukan dengan cara menghitung nilai kapasitansi kapasitor yang akan digunakan dan memasukkan program pada mikrokontroler agar kapasitor bank mampu menyesuaikan pengaktifan untuk mencapai nilai faktor daya yang diinginkan.

\section{DAFTAR PUSTAKA}

[1] Abdul Hadi, Ir. 1994. Sistim Distribusi Daya Listrik. Jakarta:Erlangga.

[2] Andrianto, Heri. 2008. Pemrograman Mikrokontroler AVR ATMEGA16 Menggunakan Bahasa C (CodeVision AVR). Bandung:Informatika.
Bishop, Owen. 2004. Dasar-dasarElektronika. Alih bahasa oleh Irzam Harmein, S.T. Jakarta:Erlangga.

Chusna A., Yahya.dkk. Perbaikan Faktor Daya Untuk Beban Rumah Tangga

Secara Otomatis. (Online). (http://www.eepisits.edu/id/ta/1680/Perbaikan-Faktor-Daya-

Untuk-Beban-Rumah-Tangga-Secara-

Otomatis). Diakses 6 April 2012.

[3] Dasar, Elektronika. Jenis-jenis Kapasitor. (Online). (http://elektronika-dasar.com/teorielektronika/jenis-jenis-kapasitor/). Diakses 8

Oktober 2012.

[4] HME ITB, Elektron. Apa itu Mikrokontroler?. (Online). (hme.ee.itb.ac.id/electron/?p=32). Diakses 17 April 2012.

[5] Lister, Eugene C. 1993. Mesin dan Rangkaian Listrik. Edisi Keenam. Alih Bahasa Oleh Ir. Drs. Hanapi Gunawan. Jakarta:Erlangga.

[6] Miztallia. Pemrograman Mikrokontroler ATMEGA8535. (Online).

[7]

(http://ml.scribd.com/doc/11571142/Pemrogra man-Mikrokontroler-ATMEGA8535). Diakses 27 Agustus 2012. (Online).

[8]

(http://saranabelajar.wordpress.com/2010/02/1 8/karakteristik-beban-pada-sistem-arus-listrikbolak-balik-ac/). Diakses 5 November 2012.

[9] Olweist, Beztta 'dedeq'. Kapasitor Adalah Komponen Elektronika Yang Mampu Menyimpan Arus Dan Tegangan Listrik Untuk Sementara Waktu. (Online).

[10] (http://ml.scribd.com/doc/32356182/Kapasitor -Adalah-Komponen-Elektronika-Yang-

Mampu-Menyimpan-Arus-Dan-TeganganListrik-Untuk-Sementara-Waktu). Diakses 10 September 2012.

[11] Teori Dasar Mikrokontroler. (Online). (grahacendikia.files.wordpress.com/2009/04/m ikrokontrl.pdf). Diakses 22 Oktober 2012 